\title{
The Behavioral Impact of Foster Care towards Middle-Aged Children and Adolescents on Their Families of Origin: A Case Study in Alice Township
}

\author{
T. Pitso ${ }^{a}$ \\ N. Maxhela $b$ \\ K. Xhongo ${ }^{b}$ \\ T. Vazi $b$ \\ a Department of Psychology, University of Fort Hare, P. Bag X1314, Alice 5700, RSA, Email: tsoloz2002@yahoo.co.uk \\ ${ }^{b}$ Department of Social Work, University of Fort Hare, P. Bag X1314, Alice 5700, RSA

\section{Doi:10.5901/mjss.2014.v5n10p644}

\begin{abstract}
Provision of care for children who have been taken from their families can be viewed as being a potentially unconvincing and fragile process in our black communities. Since 1994 the South African Government has increasingly adopted a social agenda, channeling a significant amount of effort and resources towards identifying vulnerable groups in society, crafting legislation that would protect their interests and developing and implementing programmes and strategies to support them. The qualitative study assessed the behavioural impact of children in foster care and also behavioural impact towards their families of origin in Alice, Eastern Cape Province. The open-ended questionnaires were used to collect data from 30 participants, who gave a voluntary consent. The findings of the study are that today the vulnerabilities of children, the youth, and the disabled are still inextricably linked to harsh apartheid-era legislation aimed at subjugating black South Africans and are further exacerbated by systemic poverty and inequality which continuous to manifest itself along a racial divide. Recommendations made are that there should be immediate filling of vacant posts, induction of new social workers, and provision of adequate services to liaise foster cares with the families' origin of these children.
\end{abstract}

Keywords: Behaviour, Impact, Foster, Care, Middle childhood, Adolescence

\section{Foster Care and Its Etiology}

Within the formal child care system in South Africa, foster care is normally considered to be the preferred form of substitute care for children who cannot remain with their biological families and who are not available for adoption (Ambrosino, Ambrosino, Heffernan and Shuttlesworth, 2005). This reflects the belief that the family is normally the environment most suited to the healthy growth and development of the child. According to Cohen and Garret (2006), foster care is defined as a complex of services which serves children who have experienced abuse or neglect, death of their birthparents and dysfunctional families. Children in foster care may live with unrelated foster parents, with relatives, or in group homes or residential treatment centres. The total number of children in foster care in Eastern Cape is 49382, almost $79.4 \%$ are Africans, and $9.0 \%$ being Coloureds, $2.6 \%$ Indians and $9.1 \%$ are whites.

Children can be defined as persons under the age of 18 years, and for the purpose of certain legal provisions, a person who is over 18, but under the age of 21years (Stevens and Cloete, 2004).Children comprise almost $14.9 \%$ of the Province's population. African children constitute almost 93\% of all children in Eastern Cape and are the largest group, whereas $4.2 \%$ are Coloureds, $0.1 \%$ is Indians and $4.5 \%$ are whites. Since 1994 the South African government has increasingly adopted a social agenda, channeling a significant amount of effort and resources towards identifying vulnerable groups in society, crafting legislation that will protect the interests and developing and implementing programmes and strategies to support them (Heaton, 2004). The population of children and young people in foster care has grown dramatically, and the challenges associated with achieving permanency for them have mounted.

According to Ashton (2009), the reasons why children enter foster care is because of psychosocial issues such as children being left parentless owing to AIDS. Furthermore physical abuse is probably another reason to enter our minds when we consider why a child enters foster care. According to Booysen (2007), physical abuse usually means to the extreme, where bruising is left on a child and numerous attempts to help a family learn alternative means of disciple have failed. Another commonly occurring issue is sexual abuse; this can mean the involvement of a dependent, developmentally immature child or children in sexual activities that they do not fully comprehend or to which they are unable to give their informed consent and which violate the social taboos of the culture and are against the law (Bolger, 
2008). It is extremely difficult to prove emotional abuse, but is often a part of physical or sexual abuse, which normally leads to teenage pregnancy (Babbie, 2007). Teenage mothers are ambivalent towards and clandestinely rejecting their children as they lack parenting skills as well as knowledge concerning the emotional needs of the child and as having negative 'irrational' thoughts and feelings concerning their children ,hence some of the children end up in foster in foster care (Macleod, 2003).

Poverty has always affected the well-being of children and families, it severely limits the ability of some families to provide basic necessities for their children, including food, shelter, clothing, health care, and transportation to school and needed services as a result child neglect leads to street kids. Poverty and poor health also are related (Sachs, 2005). Given the impact of poverty on the ability of many families to provide adequately for their children, it is not surprising that children living in poverty are far more likely to be reported to child protective services as victims of child neglect (Weinnberg, 2009).

According to Bachmann (2007), the disruption of the conventional family structure is most evident amongst African children; children placed with foster parents with a different background from their own may be, albeit not intentionally or directly, denied the right to enjoy their culture, or to practise their religion or to use their language. It is also unrealistic to expect from foster parents that they keep the child in touch with his or her culture, if the foster parents do not know what that culture entails (Tati, 2009). Even though there are a number of cultural factors that influence this observation, the distance between biological parents and their children may influence the extent to which resources such as for example remittances and social grants are used for the general improvement of their well-being (Stein, 2005).

Patterson (2008), argues that children in foster care deal with identity and loyalty issues, problems in discrimination between foster children and the biological children of foster parents, strains and tensions for the foster parents and their own children, redefinition of the family, behavioural problems of the foster child, feelings of loss on the part of the foster child's biological family, and the working together of the biological and foster families. According to Chase (2006), historically broader economic and political realities have affected the welfare of families and children. These factors impact the overall functioning and well-being of families, and consistently play a key role in the extent to which child abuse and neglect occur and foster care is needed (Wachipa, 2006).

Many of the same stresses that historically have been associated with increased risks of child maltreatment and the need to place children, away from their families and into foster care characterize the current economic and social environment. These factors include poverty and the effects of HIVIAIDS (Altman, 2009).

\section{The Prevailing Problems}

Even though the government of South Africa has increasingly adopted a social agenda channeling a significant amount of resources towards identifying vulnerable groups in society. Less effort has been put into establishing the extent to which service delivery has had an impact on the situation of these vulnerable groups over time (Courtney, 2004). This can be proven by the escalating number of street kids despite the presence of foster care ( Vig, 2005).

According to Courtney (2004), the increasing of foster care factors like death of biological parents, physical and sexual abuse and all other contributing factors has resulted in escalation of foster care applications which negatively impacts on quality service delivery. This state of affairs creates stress and frustration amongst the clients and the service providers, i.e. social workers. Furthermore, it impacts negatively on the quality of life of the family who has no adequate finances to provide for the needy child. In some instances the children drop out of school and engage in criminal activities and prostitution to meet their financial needs (Jackson, 2005).

\section{Factors Contributing to the Emergence of Foster Care}

A lot of factors contribute to the emerging of foster care placement and among many of those factors, parenting style, dysfunctional family, early parenthood and socio-economic factors cab noted and below is the summary of how this factors correlates in contributing to foster.

Parenting style can be classified in accordance to the degree of parental responsiveness and parental demandingness exhibited in child rearing practices .Parental responsiveness refers to the amount of warmth, acceptance and involvement (Blau, 2009) .Children raised in a neglectful environment turn to have low level of positive adjustments like school achievements, social competence and psychosocial adjustments.

A dysfunctional family is simply defined as family where one or more of the individuals are not having their needs met. When problems and circumstances such as parental alcoholism, mental illness, child abuse, or extreme parental rigidity and control interfere with family functioning, the effects on children can sometimes linger long after these children 
have grown up and left their problem families (Saleeby, 2002). Adults raised in dysfunctional families frequently report difficulties forming and maintaining intimate relationships, maintaining positive self-esteem, and trusting others; they fear a loss of control, and deny their feelings and reality.

When you grow up in a dysfunctional family, you experience trauma and pain from your parents' actions, words, and attitudes. This trauma you experienced, you grew up changed, different from other children, missing important parts of necessary parenting that prepare you for adulthood, missing parts of your childhood when you were forced into unnatural roles within your family (Landsverk, 2005). For some of you, it has led you to attempt to flee the pain of your past by alcohol or drug use. Others of you feel inexplicably compelled to repeat the abuses that were done to you on your own children or with your own spouse. Others of you have felt inner anxiety or rage, and don't know why you feel as you do (Sneidjer, 2005).

Social and economic resources shape the health of individuals and populations. Decline in family incomes, coupled with drops in nutrition, health, hygiene and education levels of children, all contribute to environmental degradation and tend to negatively impact youth the most (May, 2003). There has been an increase in malnutrition among children due to the difficult economic circumstances facing many people in the past years. Commitment to the care and protection of the children is an ethic rooted deep in promoting culture and society. According to Bachmann (2007), if provision of giant strides on the road to health and education for all, as health centers, hospitals, schools and universities can flourish in a nation which places the highest premium on human development, and which sees, in its population, it's most important resource social-economic inequalities can be overcome (Milner, 2003).

\section{Findings}

Death of parents, child neglect, physical, sexual and emotional abuse all the factors that contribute to children being placed in foster care had detrimental on the individual, family and communities making it difficult to elaborate the devastating effects of these factors on the structure of the family. However, it is apparent that the government alongside other stakeholders in contact with families at grassroots level was neglecting some of its responsibilities such as empowering community with needed resources to effectively address the challenges affecting the social structures at the family level.

Nearly all human social behaviour we consider natural and normal is learned. Childhood is not a biological stage of life that is universal and unchanging. Like parenting, it is a social construction, because the experience of childhood varies by time, place, and social location. However conditions such as those that affect the physical and emotional health of the child include inadequate nutrition, being subjected to harmful substances during the gestation period, trauma or accident, or disability, such as Down syndrome, which can reduce the capacity of the child to smile or to signal distress. This can result in the parent figure missing the attachment signals and perceiving the child as unresponsive. Hence a healthy emotional development of all children is needed to trust in the availability of a caregiver who is accessible but not intrusive, dependable, and alert to signals of need, ready to provide whatever nurture and protection is needed.

\section{Conclusions}

Foster care requires parental skill. Foster Skills is a social enterprise dedicated to empowering foster children to beat the odds, follow their dreams, and become successful and productive (Phares,2005).Its goal Enrich the lives of foster youth by providing emotional support systems, skill-building education, connecting them to resources, and advocating. This literature is a composite of empirical research articles, general information, and guides on All Things Foster Care (Babbie, 2005).

According to Jackson (2002), every child deserves a stable and lasting family life and should not be deprived of it except for urgent and compelling reasons. All children have specific needs, for street children and traumatised children this is particularly true. Children thrive the most when they live in a loving family (Kasiram, 2010). Protecting and nurturing the young is a universal goal across human cultures. The family is the important unit as the provider of safe, stable, and nurturing environments for children.

The effects of foster care remain a multifaceted challenge to individuals, families, communities and South Africa as a whole. Social workers are provided with opportunities to practice and face the unique challenges as a result of children in need in attempt to prevent these children from becoming victims of crime, child trafficking and prostitution .Communities still remain confused about what is foster care is, therefore the roles of social workers remain significant as far as monitoring such challenges is concerned. 


\section{Recommendations}

There is a need for special attention in South Africa to be given to children in need of care because from the findings of the study, most of these young children find themselves in this situation where they need to be cared for. A child is considered in need of care and protection if a child has been abandoned or orphaned and is without any visible means of support, lives or works on the streets or begs for living, is in a state of physical or mental neglect it is not by their choice that they find themselves in such situations. Every child is entitled to normal life and education. The study recommends the provision of welfare services to the children who are in need of foster and parents who are lacking parenting skills, as it was discovered that they were not adequately supported. Therefore, it can be suggested that their services are immensely required in providing training, support and skills to the children who are in foster and foster parent's .Also to deal with the issue of judgmental to the communities about foster because children are all the same. The knowledge gained through parenting skills and support will go a long way in addressing the issue of judgmental, lack of social skills is rooted in lack of knowledge concerning foster care hence leading to stigmatization. As foster care faces new and increasing demands, policies and practice must respond in ways that ensure that children, their families, and their caregivers receive the highest quality service possible

Based on the findings of this study, the group makes the following recommendations for practice and for further research. The government should come up with additional strategies to combat the problem of intergenerational vicious cycle of children in need among the most disadvantaged communities. There has to be additional educative programs courses which will be provided in communities by skilfully trained professionals such as, psychologists, social workers and community based workers in order to help them to acquire necessary skills to combat the daily psycho-social problems and equip them with self-awareness, self-acceptance and self-esteem. The study recommends the provision of social work services to the care givers as it was discovered that they were not adequately supported. Therefore, it can be suggested that their services are immensely required in providing training, awareness campaigns, support and skills to the caregivers as well as to facilitate anti-stigma and discrimination campaigns. The knowledge gained through awareness will go a long way in addressing the issue of social discrimination which is rooted in lack of knowledge concerning foster care hence leading to stigmatization.

\section{References}

Amoateng Y, Heaton, T and Kalule-Sabiti, I. (2004). Living arrangements in South Africa. In: Families and households in Post-Apartheid South Africa: SocioDemographic perspectives. Pretoria: HSRC.

Ashton, V. (2009). Worker judgments of seriousness about and reporting of suspected child maltreatment. Child Abuse \& Neglect.

Altman,M, Hart, T. and Jacobs, P. (2009). Food security in South Africa. Human Sciences Research Council: Pretoria.

Babbie, E. (2007). The practice of social research, 11th ed. Belmont: Thomson Wadsworth.

Blau, Judith and Moncada, A. (2009). Human Rights: A Primer. Boulder: Paradigm Publishers.

Bolger, K. E., Patterson, C. J., \& Kupersmidt, J. B. (2008). Peer relationships and self-esteem among children who have been maltreated. Child Development, 69, 1171-1197.

Booysen, F.L.R. and Bachmann, M. (2007). Poverty and Growth: Evidence from a Household Impact Study conducted in the Free State Province, South Africa. Paper presented at the Annual Conference of the Centre for Study of African Economies, 18-19 March. Oxford, UK: St Catherine's College.

Chase-Handsdale, P.H, Mott, FH. Brooks-Gun, J \& Phillips, D.A. (2006). Children of the Nation Longitudinal Survey of Youth: A critique Research Opportunity. Development at Psychology

Cohen, M.C. \& Garret, K.J. (2006). Breaking the focus rules: A group work perspective on workers group research. British Journal of Social Workers, 29:359-372.

Courtney, M. E. (2004). Research needed to improve the prospects for children in out-of-home placements. Children \& Youth Services Review.

Crouch, J. L., \& Milner, J. S. (2003). Effects of child neglect on children. Criminal Justice and Behaviour.

Jackson, S.L. \& Stein, L. (2005). Research Methods \& Data Statistics: A Critical Thinking Approach. London: Thomson Wadswoth.

Landsverk, J.(2005). Developmental and behavioral needs and service use for young children in child welfare. Pediatrics.

May, J., Macleod, \& P. (2003). Chronic Poverty and Older People in South Africa. Chronic Poverty Research Centre Working Paper no. 25.

Sachs, J D. (2005). The End of Poverty: Economic Possibilities for Our Time. New York: Penguin.

Perumal, N. And Kasiram, M. (2010). Children's homes and foster care: Challenging dominant disclosure in South African Social Work Practice. Social work/ Maatsskaplike Werk Journal Vol. 44, No 2.

Schneider, K. M., \& Phares, V. (2005). Coping with parental loss because of termination of parental rights.I Child Welfare.

Saleebey, D. (2002). The Strength Perspective in Social Work Practice (3rd Ed). Allyn \& Bacon: New York.

Stevens. R. \& Cloete M.G.T. (2004). Introduction to Criminology. Oxford University Press of Southern Africa (PTY) Ltd, Cape Town.

Tati, G.(2009). Elderly headed households, markets and consumption in urban South Africa. Paper presented at the 7th International Science Conference on the Human Dimension of global environmental change, held in Bonn. Retrieved on 1 November 2009.

UNFPA. (2005).Operational Guide on Gender: rights-Based Approach. KIT Publishers: Amsterdam.

Van Zyl, J \& Kirsten, J. (1992). Food security in South Africa. Agrekon, 31 (4): 170-184.

Wachipa, B. (2006). Older persons' right of access to social assistance. Is age differentiation still relevant in South Africa? ESR Review: Economic and Social Rights in South Africa.

Weinberg, L. A., Zetlin, A. G. \& Kimm, C. (2005). Helping social workers address the educational needs of foster children. Child Abuse \& Neglect, 29, 811-823. 